UDC 811.111’37’367+551

\title{
SEMANTIC SPACE OF THE RESEARCH PAPER ABSTRACT
}

\author{
Tetiana Mironchuk, \\ $\mathrm{PhD}$ in Philology, Associate Professor \\ of Foreign Department for Natural \\ Sciences Faculties, \\ Taras Shevchenko National University \\ of Kyiv, \\ Kyiv, Ukraine \\ tatianakiev99@gmail.com
}

\author{
Natalia Odarchuk, \\ $\mathrm{PhD}$ in Philology, Associate Professor \\ of Conversational English Department, \\ Lesya Ukrainka East European \\ National University, \\ Lutsk, Ukraine \\ natalylutsk@gmail.com
}

Received April, 9, 2018; Accepted May, 7, 2018

\begin{abstract}
The article explores semantic structure of the abstract of geological research papers (GRPA) and proposes a model of its semantic space. Consideration is given to the functional level. Its semantics is concluded to be built by two segments of content - referential and textual ones.

GRPA is defined to be a super-segmental sign of secondary denotation and co-reference, which reflects a complex system of semiotic, semiological, and textual relations between two lingual signs the research paper and the abstract. GRPA referential semantics is studied via the GRPA semiotic relations and establishes coding, patterning, and indexing functions to frame GRPA semiotic semantics, while also recognizing instrumental, indicatory, identifying, substitution, and compensatory functions to be complementary to the GRPA semiotic nature.

GRPA semiological relations establish reportive, referential, and reflective functions to be fundamental to GRPA textual semantics, which is supplemented by informative, visualizing, and educative functions. Informativeness, evidentiality, and credibility are determined to constitute core attributes of the GPRA functional semantics. The descriptors of informative semantics of the texts of academic genres and the GRPA, in particular, are concluded to be the predicates of existence, state, identification, movement, physical and intellectual action, location, and characterization.
\end{abstract} semiotics

Keywords: textual reference, functional semantics, syntactic semantics, academic genre texts,

\section{Introduction}

The present-day advances in technologies and sciences result in thriving media and publicism with sensational news, obsessive analytical reviews and data analysis, which affect mental health of the media content users. The social motive "to be informed" loses its attractiveness, for natural inability of the human mind to process bulky articles, wide-ranging discussions, or volumetric data. Still, the social need to be knowledgeable or aware of the latest news in global technologies seeks alternative genres of media or publicistic prose that might suffice relevant information at minimal expense. Thus, both the principle of language means rationality and the global trends for minimizing size and effort prioritize compact genres of text information, among 
which top ranked are encyclopedic entries, index files, subject headings, glossaries, summaries, abstracts, précis, synopses, etc.

Given the available sources, the notion of the abstract does not seem an unexplored field in linguistics at first sight. The study of the abstract in terms of semiotics stems from sciences and is defined as machinery processing of the information (Schmidt, 2009). Shannon C. added to the investigation of the communicative nature of the abstract via mathematical modulation operations in terms of signal-to-noise compression ratio of the inferred message (Shannon, 1986).

Linguistically, the abstract was primarily explored via stylistics and grammar and defined as an adapted or abridged text (Arutiunova, 1976; Meleshkevych, 2011; Radzievskaia, 2008) or concise and secondary delivery of the scientific knowledge (Radzievskaia, 2010; Cherkunova, 2011). Basically, linguists' attention was paid to style and genre forming lingual means of meaning explication in the text of an abstract (Shulinova, 2010). Currently, the notion of the abstract is being studied via corpus linguistics (Demska-Kulchytska, 2003) and by working out the ratio of thematic vocabulary in academic communication (Leong \& Toh, 2018).

What makes a research gap in the area of the linguistic interpretation of the abstract is absence of a content scope approach to it. An all-encompassing study might incorporate principles of semiotics, semantics and pragmatics to work out the essence of the abstract as a super-segmental communicative sign that verbalizes the content of a source text that in its turn represents a fragment of scientific knowledge.

The analysis of the text samples, not alone abstract ones, made it possible to claim abstract text semantics to be multi-layered in representing its meaning. Formally, the text of the abstract verbalizes its meaning not only lexically or syntactically. The overall semantics of the text of the abstract also involves the pre- and nonverbal constituents that reveal their meanings in the structure of the text of an abstract.

Thus, the focus of the study in this article is the Geological research paper abstract (GRPA). The subject-matter is functional semantics of the abstract. The article being aimed at understanding the referential features of the abstract as a smallsize genre of text linguistics, the following tasks seem apt:

- realizing how scientific knowledge is represented in the text of the GRPA;

- proposing a model of the GRPA semantic space;

- singling out the GRPA semiotic functions;

- revealing types of syntactic semantic relations in the text of the GRPA;

- identifying what semantic attributes make the core of the GRPA text semantics;

- discriminating classes of the predicates that verbalize informative semantics of the GRPA.

The study carried out is based on the methods of semantic modeling of the text, definition analysis, analysis of syntactic relations, contextual analysis, elements of content analysis.

\section{Geological research paper abstract semantic space}

Semantics is known to describe a lingual unit in terms of descriptions (i.e. attributes) (Arutiunova, 1976; Katz, 1963). Complex and non-linear lingual units, texts in particular, are not elemental in nature. Subsequently, this makes their 
semantics also multidimensional, for it is made up of the whole scope of content of a lingual unit. We suggest super-textual units' semantics incorporate heterogeneous semantic systems, i.e. their semantics is poly-paradigmal (Terekhova, 2017: 178). When dealing with semantics, we follow D. Katz statement that "linguistic description minus grammar equals semantics" (Katz, 1963: 173).

In approaching the research paper abstract, our bench-mark is to consider the abstract a product of a gnostic, epistemic and cognitive scientific activity, as well as a genre of the scientific or academic written communication. We postulate the abstract to be both a concise, derived propositional text of a source text and a micro- structure that represents a domain-specific terms system and generalizes domain-experts findings.

Being a whole system itself, the semantic structure of the GRPA can be modeled as an orderly arranged complex of both discreet and integrative surfaces, each of which is over-layered by a more extended set of relations. The layers are hierarchically discriminated as notional, topical, functional, communicative and metacommunicative ones.

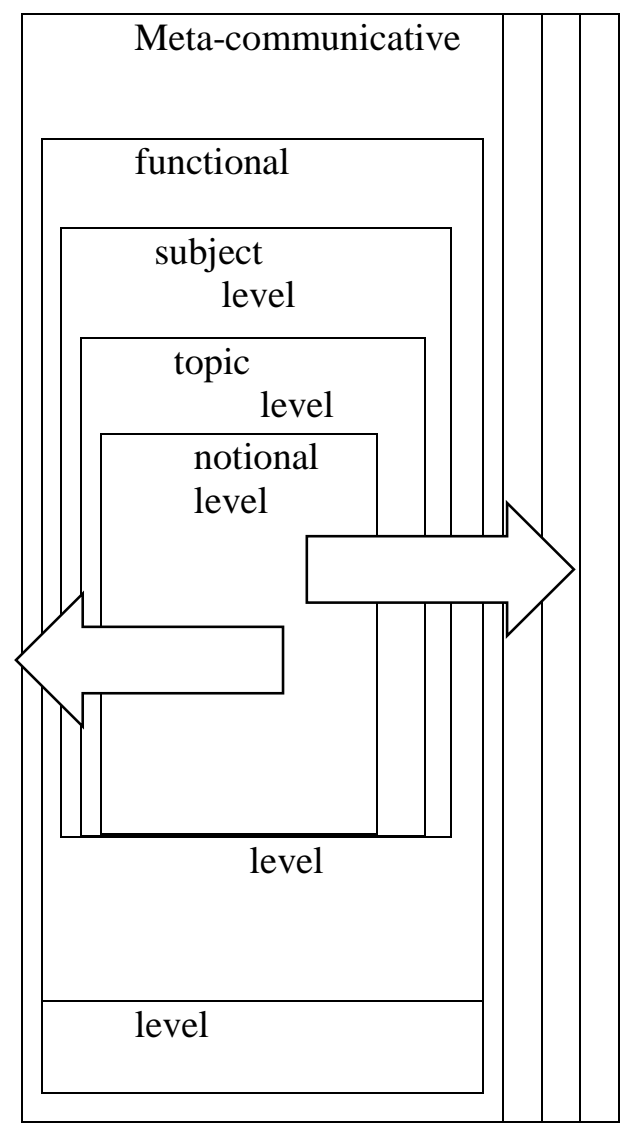

Figure 1. GRPA Semantic Space Model 
We suggest the GRPA semantic space develops as a system outward from the notional layer, which constitutes its core and makes the GRPA's intrinsic semantics, to the meta-communicative layer, which incorporates social functions of the GRPA into its semantics. By this we admit N. Fairclough's viewpoint that discourses reflect speakers' systems of knowledge or worldview sets, and can be referred to as "the domains 〈...〉 for regulated practice" (Fairclough, 2000: 133-134). As a piece of a written academic discourse, the GRPA represents cognitive operations of knowledge in a text structure, making its semantics heterogeneous and efferent.

Thus, the notional layer of the GRPA semantic structure is composed of the nucleus lexes that determine the notion of the abstract. The topic layer pinpoints the areas of the research in earth sciences, and is revealed through topical field vocabulary and domain specific terms. The subject layer is assumed to schematize the structure of the abstract as a piece of academic prose; thus its constituting semantics refers to the analytical and categorical lexes that highlight the title, literature overview, research gap, research focus and outcomes, i.e. nominate GRPA compositional parts. Besides, this layer makes a matrix for text semantics by building a compositional skeleton of text relations.

Unlike the previous layers, whose semantics is confided to lexical one, a functional layer is presumed to actualize text semantics through a variety of text categories and relations. It is here where the words make sense, being incorporated into syntactic chains, words sequences and rows. By doing this, the lexes and clauses acquire adherent lexical and syntactical charges. Concerning the GRPA, its functional semantics is represented by text categories and functional relations that determine abstract's academic genre features. Those are text local coherence, gnostic and epistemic evaluation. A further specification of syntactical text integrity reveals through a network of cause and effect relations, relations of contrast, concession, and addition, which manifest consecutive, concessive, additive, summative, and clarifying syntactic semantics.

The final layer, meta-communicative one, has to do with social applications of the abstract. Here, it is tackled as a discursive sign - a speech and a discourse act. The outermost layer involves additional characteristics of the abstract as a lingual unit. The abstract is viewed as a message, i.e. an element of the information chain involving a sender, a recipient and a channel. The presence of a person in a model of communication gives rise to the involvement of the logical categories of deduction, inferences, and pragmatic categories of presupposition, implications, perlocution in the GRPA outer semantics. Globally, the GRPA primary functions to inform manifests in speaker's intention and the presumed perlocutionary effect - the change of the cognitive state of a recipient. Formally, it is verbalized through assertive speech acts.

This paper will focus on the GRPA saliences that are revealed at the functional level of the proposed model. We assume GRPA semantics at this level to be composed of two segments of content, referential and textual, in particular. Further, the GRPA functional semantics will be studied via the categories of semiotics, reference, relations, function, and predication. 


\section{Functional level: \\ General semiotics of the research paper abstract}

Preverbally, the GRPA represents a cognitive scheme of specialized scientific knowledge that is actualized in a system of notions and domain-specific terms. If to consider a research paper text to be an imprint of a specialized scientific worldview, the text of a research paper abstract is, consequently, a condensed way of generalized scientific knowledge that is explicated in a research paper. Viewed via referential semantics, the GRPA arises as a co-referential lingual sign that relates cognitive and lingual activity; specifically, there builds a link between knowledge and scientific information on the one hand (both functioning beyond language), and the text of a research paper and the text of an abstract (both functioning in language), on the other hand.

This relation can be schematized as the following operational chain:

empiric experience (knowledge acquisition) $\rightarrow \rightarrow \rightarrow$ knowledge categorization and generalization (scientific information) $\rightarrow \rightarrow \rightarrow$ conceptualization of abstract notions (domain-specific terminology frame) $\rightarrow \rightarrow \rightarrow$ formalization of the sense chunks in a system of verbal signs (research paper text, text of scientific prose, academic text, etc) $\rightarrow \rightarrow \rightarrow$ (meaning attribution to a research paper text) $\rightarrow \rightarrow \rightarrow$ secondary coding and verbal denoting (patterning the text of an abstract) $\rightarrow \rightarrow \rightarrow$ deciphering primary text meaning (abstract text meaning attribution) $\rightarrow \longrightarrow \rightarrow$ multi-spatial co-referential digesting (linking pre-, primary and secondary texts meanings in a conventional system of information decoding).

Semiologically, the GRPA reflects essential information of a source text (a research paper text) and comes across as a complex lingual sign of double denotation - primary denotation of a scientific worldview fragment in a research paper text is coded by secondary denotation of a generalized scientific worldview fragment in an abstract text in a more refined mode. Thus, by patterning and codifying source text information, a lingual sign of the GRPA deciphers text meaning anew, which is why there form two systems of macro- and micro-texts (the source text and the abstract text, correspondingly). This reveals formally through the asymmetry in the planes of expression between both signs. Although smaller in size, the text of an abstract carries a more substantial message charge as compared to the text of a research paper. The asymmetry is due to the "minimizing the formal plane and maximizing the plane of expression" (Radzievskaia, 2010: 284-286), which is indicative of the concise text genres.

\section{Functional level: GRPA referential semiology}

A scrutinized analysis of the GRPA semiotic features made it possible to recognize an array of functions that are manifested in the content structure of abstract's functional semantics. Coding, indexing, and patterning, being the primary functions of semiological relationships, acquire specific treatment when correlating two lingual signs - a text and an abstract.

In an abstract, coding function comes across as an algorithm that decodes text information as a key message by applying a conventionally accepted lingual system 
of interpretation. In the case of an abstract, an operation of decoding should restore a full scope of the information contained in the text of a paper.

Indexing in general semiotics refers to readdressing a sign to a related system or context, i.e. establishing the initial sign deictic relations by comparing the magnitude of a sign with the standard. When projected onto a notion of the abstract, its indexical function lies in building a ratio between the amount of the information contained in a research paper text and the one contained in an abstract. This quantitative relation reveals the property of an abstract, being secondary to a primary sign of a research paper, to measure the referent meaning, or, to be more specific, to assess the informative value of a message expressed through the lingual sign of an abstract as compared to the one in a research paper.

Patterning, overall, means an application of a set of rules to systemize information. Relative to an abstract, patterning suggests a chain of logical and cognitive operations that suffice codifying empirical knowledge of a research topic, first, in a text of a paper, then, in a concise and semiologically structured text of an abstract. Both the text of a research paper and that of an abstract, require arranging the information in sets of sequences and repeated flows. Thus, the structures of both reveal incongruence concerning the size, as a measure of length of each sign, but certain congruence concerning the compositional regularities of both signs, and, more importantly, full congruence of an abstract sign to a research paper sign in terms of content sameness and informative identity of the former to the latter.

Further speculations about the network of semiological relations between an abstract and a research paper causes to anticipate some additional semiotic functions intrinsic of the nature of an abstract. Close to the coding function is an instrumental one. The instrument, being an implement or a measuring device, relates something as a means to an end. In the case of an abstract semiology it serves a reliable tool to catalogue and compile information into the corresponding categorial files and/ or niches. Namely, the GRPA refers to a genre category of little format texts, and academic referential texts. Genre and functional categorization enable singling out another function, an indicatory one that refers the abstract meaning to a certain informational branch, which in the case of academic genres is a domain of specialized scientific content. When speaking particularly about the GRPA, the key words and the terminological lexes place a research paper in the niche of natural, and more specifically, earth sciences.

An identifying function, a derivative of patterning, seeks sameness or identifies equivalence of the abstract text meaning and the source text meaning. A substitution function reveals itself through the reciprocal relationships between the source text and the abstract text and lies in replacing the source text meaning of a research paper with the abstract text meaning. A compensatory function of an abstract shows itself in the semantic sufficiency of the information actualized in the abstract text in relation to the one of a research paper.

Besides the discriminated functions, based on the dominant semiological relation, the abstract has some social applications. Among the most vivid ones are educative, visualizing, and informative functions. Like any piece of science or publicism, a research paper abstract is meant to educate by communicating knowledge to a reader in the broadest sense, not alone scientists. The text of an abstract enhances addressee's general intellectual awareness and educational competence. The general educative 
potential of an abstract is targeted at an average recipient, but its informative charge is intended for domain-specific experts as it provides an insight into a specialized scientific domain. Domain-specific information delivered in the text of an abstract comes across as a step-by-step algorithm of reaching a final conclusion in the research, by this narrowing common scientific information to make it look like a chain of sophisticated intellectual instructions perceived by highly skilled experts in a research area. And finally, a visualizing function. Graphic, pictorial, chart, and diagram representations of the information are claimed to be common for the texts of natural sciences (Armer, 2011; Powel, 2013), for the former designate the essentials in the concise and visual way, and become icons to the text information. Formulae, algorithms, chemical symbols being among the primary non-textual graphic signs in the GRPA, are convenient means to render information or a message. Firstly, they are compact as compared to the verbal signs; secondly, they are well remembered, for which they are considered to be both informative and expressive; and thirdly, which is more important, they visualize verbal information in a sophisticated way making links between the rational and irrational channels of perceiving and processing monotonous verbal information.

Concluding, the GRPA functional semantics studied within the frames of the general semiotics enabled revealing a complex double referential semiotics of the GRPA. Namely, first a fragment of scientific knowledge is denoted and formalized in the text of a research paper, then it co-refers with an abstract and is denoted in it, for which the GRPA is claimed to be a semiotic sign of secondary denotation.

Semiotic nature of GRPA primarily fortifies coding, indexing, and patterning functions, while also recognizing instrumental, indicatory, identifying, substitutional, and compensatory ones. Besides, semiological relations discern educative, visualizing, and informative functions within GRPA functional semantic space.

\section{Functional level: GRPA textual semiology}

The study of the GRPA text and functional semantics can be done based on the theory of reference, which classically claims that any sign (a word or a text, including) manifests a number of relations with other things or reality (Sperber, Wilson, 1996; Zelinsky-Wibber, 2000).

In our paper the referential properties of the GRPA will be given an overview in the paradigm of functional logic, which generally claims that the denotate (a word or a text) has a meaning because it stands for something in a real world (a thing, an event, a fragment of reality). In this sense, we assume that the text of an abstract redenotes the text of a paper and finds reference both in the text of a paper and the fragment of scientific knowledge.

This is due to the fact that secondary codification of the abstract text meaning (as compared to the text of a research paper) generates a higher degree of meaning abstraction and integration and requires a conventionalized system for a recipient to decipher the meaning coded in the text of an abstract. Hence, alongside with the functions of the abstract as a sign of general semiotics designated above, there can be distinguished some systemic functions of the text 
of an abstract as a super-segmental lingual sign. These were established to be reflective, reportive, and the referential functions.

Reflective function avails the abstract text to provide a concise representation of a specialized scientific worldview fragment. At the verbal layer this function is explicated by the terminological nominations inherent of the specialized research topics and fields. The study of the resource base of the GRPA identified the following classes of lexes to be recurrent: general scientific lexes (assessment of the prospects, morphogenesis, evolution, reservoirs); general geosciences lexes (continental crust, tectonic movements, gabbro-anorthosite massives, gas hydrate-bearing sediments); specialized geological lexes (synthetic wave field, seismic profiling stressstrain, Enhanced Oil Recovery (EOR) technologies); general technical lexes (mining industry, electric kinetics, drainage channels, resistivity, engineering); mathematical lexes (angle, triangular-prism-shaped, inversion, regression analysis, numerical technique, iterative method); physical lexes (magnetotelluric, electric conductivity, heat flow, GIS, tomography); chemical lexes (gold, salinity, sulphates, chlorides, isotope); geographic lexes (coastal lowlands, topographic, relief, PANCARDI, Pannonian Basin, Pre-Azov Region, Ukrainian Shield, Yenisei Ridge), and biological lexes (diatom, algae). Additionally, the topics covered in the GRPA were found to actualize the semantics of specialized-domain academism and innovativeness (suevits, feldspar norites, ophiolites, paleoterreyn fluidolites, picrites).

Reportive function reflects the source text semantics in terms of secondary narrative: the substance of a research paper is projected on an abstract and verbalized anew, i.e. retold in a concise way. The abstract makes a mould or a frame that embeds a paper content, by this being finer environment as compared to coarser environment of a research paper. While semiotically tackled as an organizational structure that reshapes the composite content of a research paper and arranges it as a compendium, the very abstract text actualizes also semantic text relations and text categories. The composition of the GRPA reveals basic textual architecture - the syntactic relations of cause and effect, coherence and cohesion, consequence and contrast, addition, clarity, and narration. The scrutiny of the verbalizers that actualize syntacsemes might be a subject matter of a separate study.

We postulate referential function to be most closely linked to the reflective one, or to be more precise, a derivative of it, for it carries the bulk of the information in a research area and a charge of the denotative load. In the semiological triangle the signified $\rightarrow$ the referent $\rightarrow$ the denoted, the subject matter of a research paper is signified as findings and denoted through the abstract key words, topic or statement sentence, and domain-specific lexes.

Summing up, the referential semiology theories made it possible to single out reflective, reportive, and referential functions in the GRPA functional semantics.

\section{Functional level: GRPA semantic category of informativeness}

Apart from being an inherent feature of an array of modalities and propositional judgements, informativeness is tackled in logic and linguistics as the foundation for the truthfulness of judgments (Parafragou, 2006: 1690; Radzievskaia, 2008: 151; 
Pryhodko, 2015). We claim informativeness to make the core of a research paper, and, notably, a research paper abstract. The study of the informative semantics of the GRPA was held on the two layers discriminated in the proposed model, namely, the subject layer and the functional layer.

At the subject layer consideration was given to the lexes that frame the compositional structure of the GRPA - topic sentence which pinpoints lacunarity of the research in the area and substantiates its relevance; subject matter of a research procedure with preponderance of methods and instruments; findings and keywords. The definition analysis of the lexes recurrent in each compositional part revealed the prevalence of two major semes of informativeness - credibility and evidentiality.

The semantics of credible informativeness is actualized in the GRPA compositional parts that denote a procedure of research - carrying out an experiment, doing an analysis, making comparisons, verifying a hypothesis (The data of that analysis were then compared with current research to examine ...; ... maps produced by this method were found to be more reasonable..., ... was analyzed to ascertain the actual distribution of rainfall...).

The semantics of evidential informativeness, though, is actualized in the GRPA compositional part that focuses on the results and findings through the meanings of provableness, demonstrability, evidence, and facticity (our model provides the first seismic evidence...; experimental results reveal...; ...enables us to present the first detailed outcrop analysis...; these results confirm...).

The GRPA informativeness is significantly enhanced by statistical data (increasing the density from 1200 to $2100 \mathrm{~kg} / \mathrm{m}^{3}$; a $20 \%$ increase in the velocity reduction ratio; less than the minimum 0.5 values reported from thrusts; an Early Cambrian (526.3 $\pm 12 \mathrm{Ma})$ metamorphic age; with estimated potential incremental recovery of up to $12 \%$; about $110 \mathrm{MMbbls}$ (million barrels of crude oil; real data for the earthquakes of $24.04 .2011\left(13^{h} 02^{m} 12^{s}, 35.92^{\circ} \mathrm{N}, 14.95^{\circ} \mathrm{E}\right)$, formulaic symbols, and numeric values (benjaminite $(\mathrm{Ag}, \mathrm{Cu})_{3}(\mathrm{Bi}, \mathrm{Pb})_{7 \mathrm{~s}_{12}}$; telluronevskite $\left(\mathrm{Bi}_{3} \mathrm{TeSe}_{2}\right)$; rareearth bearing $(\mathrm{Nb}-\mathrm{Zr}-\mathrm{RE})$ specializations; $V_{p} / V_{s}$ shear ratio; silver content (from 0.06 to $2.66 \mathrm{~g} / \mathrm{t}$ ); internal pressure from 0.6-0.8 $\mathrm{GPa}$ to $1.5 \mathrm{GPa}$;

$$
\mathrm{h}_{\mathrm{i}}=\frac{\mathrm{R}}{\mathrm{n}}=\frac{\mathrm{X}_{\text {max }}-\mathrm{X}_{\text {min }}}{\mathrm{n}}
$$

Concurrently, the study of the functional semantic category of informativeness was carries out syntagmatically based on the types of the logical syntactic relations suggested by N. Arutiunova (Arutiunova, 1976: 214-215) and the types of the predicates studied and classed by A. Mustayoki and L. Meleshkevych (Mustayoki, 2006; Meleshkevych, 2011). In our analysis we noticed the GRPA to realize the four types of the predicate relations singled out by $\mathrm{N}$. Arutiunova, namely, the relations of the existence, identification, nomination, and characterization (Arutiunova, 1980). The taxonomy of the predicate relations proposed by A. Mustayoki (Mustayoki, 2006) specifies the former one (Arutiunova, 1980) by introducing sundry particular subclasses, such as the predicates of being, state, action, motion, relation, location, etc.

The major predicate class in the GRPA is made by the existence predicates. The predicates of existence, represent an all-encompassing category of being and manifest themselves in the GRPA through the attributes of facts, presence of the 
research object, or its occurring (to be, to occur, to abound, to be present, etc), as well as through the aspectual grammatical and semantic attributes of finding, revelation, acquisition, and phase. These deep-structure predicative relations are formalized by the following verbs and phrases: to be found, to turn out, to become, to keep, to remain, to proceed, to stop (growing/ sedimenting/ alternating ... etc).

1. E.g. "In South Dakota, erionite has been found within Tertiary strata at several locations..." (Geology).

It is characteristic of the GRPA predicates of being to be modified by further semantic gradations and to form their own subclasses. Thus, within the predicates of state, recurrent were found the predicates of the state of the phenomenon, the state of the research object, or the state of the geological environment. It is worth clarifying that we consider a predicate to be an attribute of its referent, which is why the semantic predicate does not always coincide with the syntactic predicate, for the semantic predicate may often incorporate the semantics of its grammatical actant to fully actualize its descriptive function:

2. E.g. "The actual distribution of rainfall upon slopes exhibits varying inclinations and slope aspect" (Environmental \& Engineering Geoscience).

The predicates of action rank second most abundant predicates within the group of the predicates of being. They realize the semantics of a change in the physical and gnostic parameters of a research paper object. The GRPA predicates of action can be grouped into a class of the predicates of the physical action/motion and a class of the predicates of the intellectual action. The first ones reflect ontological properties and parameters of a research paper object - the genesis of a phenomenon, a change, a process, a motion (to generate, to form, to shift, to accumulate, to accommodate, to shape, to reduce, to increase etc).

3. E.g. "The velocity reduction ratio increases with an increase in the density..." (Journal of Structural Geology).

The second ones reflect gnoseological properties of a research paper object, its property to be studied in the first turn. For this reason this class predicates are lexicalized by the verbs and phrases of epistemic semantics, which, on the one hand, manifest the presence of a doer in scientific processes, and, on the other hand, validate research paper credibility and the truthfulness of the conclusions and findings (to indicate, to examine, to suggest, to confirm, to compare, to assess, to support, to ascertain, to measure, to calculate etc).

4. E.g. "Analysis confirmed the presence of zeolites in each sample at concentrations <1\%" (A Case Study of Medical Geology).

The predicates of the identification are the third largest class of the predicates that form the GRPA informative semantics. We consider this hyperclass to be categorial to the GRPA, for by nominating an object and identifying it with the denotate and the referent, there takes place correlating the name with the class, species, genus, etc. Besides, the predicates of the identification can serve as the classifier. The deep semantic level reveals the attributes of the belonging (relation), and location in their semantic structure. The syntactic structure formalizes the above mentioned attributes not only by the verbal predicates (to identify, to determine, to define etc), but also by the nominal predicates (to be / to make continental cores), and by the predicate-adverbial groups (to consist of more than 50 drumlins, to be 
composed of beds, to be associated with recent surges, to be exposed as basement inliers etc.).

5. E.g. "Erionite is... classified as a Group 1 known respiratory carcinogen" (A Case Study of Medical Geology).

The GRPA predicates of the characterization reveal the semantics of the inherent and adherent properties of a research paper object, and by contrast with the predicates of the identifying relations are topped by the possessive, causal, and locative attributes. In the syntactic structure these semantic properties are formalized by verbal, nominal predicates, as well as predicate complementary and circumstantial groups (to be sourced from the Albany-Fraser Orogen; to belong to the Laramide orogeny; to be constrained from Rayleigh wave data; to be present at depths; to be triggered by... etc.).

6. E.g. "A low-velocity column is also present in the central-eastern craton at depths of 115-250 km" (Netherland Journal of Geosciences).

We conclude the text category of informativeness to make a semantic core of the GRPA. It is actualized through the semantics of credibility and evidentiality and verbalized in the lexes that denote experiment and/ or analysis stages and findings through the meanings of provableness, demonstrability, evidence, and facticity in the statistical data, formulae, and numeric values. Syntactically, the semantic category of informativeness is actualized in the predicates of existence, identification, and characterization which are subclassed into the predicates of being, state, motion, change, physical and intellectual actions, location, belonging, and causation.

\section{Conclusion}

The semantics of super-textual units, which GRPA belongs to, is not lineal; therefore, it cannot be confined exclusively to the lexical meanings of the words. Rather, being dimensional, the GRPA semantics makes a hierarchically organized system of spaces or levels, which we represent in a semantically efferent model of "embedded surfaces" and arrange as notional, topical, subject, functional, and metacommunicative ones, meaning the notional level to be semantically inherent, with each next level to incorporate GRPA adherent attributes.

The total GRPA semantics is supposed to be made by the semantics of the constituting lexes, the semantics of the logical relations at both cognitive and formal syntactic levels, the semantic semiology of the whole text of GRPA, as well as by its communicative and pragmatic potential.

The GRPA semantics of the functional level, which the article gives thorough consideration, is assumed to be composed of two segments of content, referential and textual ones. The study of the GRPA referential semantics allowed for elucidating GRPA general semiotic features. The study of the GRPA textual semantics made it possible to establish primary and complementary semiotic and semiological functions.

Viewed through a theory of functional reference, the GRPA is a complex coreferential sign of double denoting a scientific worldview fragment. First, a scientific worldview fragment is denoted in the text of a research paper; then, the denotation of a scientific worldview fragment is projected onto the text of an abstract, being secondarily re- 
denoted and co-referred with scientific reality. A chain of coding and deciphering scientific information generates micro- and macro-semiotic relations in a system of "scientific research paper text" - "scientific research paper abstract text."

The primary semiotic functions of the GRPA are established to be coding, indexing, and patterning, which are complemented by instrumental, indicating, identifying, substitutional, and compensatory ones.

GRPA coding lies in providing a ciphering-deciphering algorithm for eliciting a full volume of a text; indexing establishes GRPA magnitude deixis; by patterning empirical and scientific knowledge of earth sciences is codified in terms of semantic congruence between a research paper and a research paper abstract; GRPA instrumental function compiles geological scientific information in a niche of little format academic referential texts of specialized scientific content; by identifying there is established semantic sameness between the two texts - a text of a paper and an abstract text; GRPA substitutional function reciprocates semantics between the two texts; GRPA compensatory function suffices the volume of scientific information in GRPA.

Semiological relations in the GRPA viewed both as a sign and a text enable eliciting GRPA educative, visualizing, and informative functions (when tackling GRPA as a sign) and GRPA reflective, reportive, and referential functions (when characterizing GRPA as a text). GRPA educative function enhances addressee's intellectual awareness; visualizing and informative functions provide vital data and findings iconically through creolized texts (mathematical symbols and formulae, chemical elements, graphs, etc.).

GRPA referential function relates the text of an abstract to the text of a paper and the fragment of scientific knowledge. GRPA reflective function embodies research paper semantic sameness in the terminological nominations inherent of the specialized research topics and fields. GRPA reportive function re-narrates the research, by this making its propositional semantics frame.

The GRPA referential semantics manifests itself in an array of semantic attributes. Informative semantics is established to make the core of the GRPA textual semantics. It is explicated through functional-semantic operators of truthfulness, credibility, and evidentiality.

These were identified based on the definition analysis of the lexes recurrent in the structural parts of the GRPA composition and the predicates. The predicates that are charged with the attributes of existence, state, movement, intellectual action, location, identification, and characterization were concluded to be the descriptors of the informative semantics in the GRPA.

Further research of the GRPA semantics is seen logical to be carried at the next meta-communicative layer as proposed in the model of the GRPA semantic space.

\section{References}

Arutiunova, Natalia. 1976. Predlozhenie i Yego Smysl. Moscow: Nayka.

—. 1980. "K Probleme Funktsionalnikh Tipov Leksicheskogo Znachenia". In: Aspekty Semanticheskikh Issledovanij: 156-249. Moscow: Nauka. 
Demska-Kulchytska, Orysia. "Bazovi Poniattia Korpusnoii Linguistyky". 2003. In: Ukrainska Mova 16: 40-45.

Meleshkevych, Larysa. 2011. "Predykaty Identyfikatsii $i$ Kharakteryzatsii $v$ Anglomovnych Tekstakh Entsyklopedychnykh Statei: Semantychni $i$ Funktsionalnohramatychni Osoblyvosti." PhD diss., Kyiv National Linguistic University.

Mironchuk, Tetiana, Pastushenko, Tetiana. 2017. "Funktsionalnyi Riven Semantyky Tekstu Naykovoii Anotatsii." In: Linguistichni ta Metodychni Problemy Vyvchennia Inozemnykh Mov na Pryrodnychykh Fakultetah: Mizhkafedralniy Zbirnyk Naukovyh Prats 4: 26-37. Lutsk: PP "Ivaniuk".

Mustayoki, Arto. 2006. "Teoria Funktsionalnogo Sintaksisa: ot Semanticheskih Struktur k Yazykovym Sredstvam.” Moscow: Yazyki Slavianskoi Kultury.

Radzievskaia, Tatiana. 2008. "Spravochno-informatsionnyi Tekstotip i Stilistika Istinnosti.” In: Logicheskij Analiz Yazika: Mezhdu Lozhiu i Fantaziej: 151-158. Moscow: Indrak.

—. 2010. Narysy z Kontseptualnoho Analizu ta Linguistyky Tekstu. Tekst. - Sotsium Kultura - Movna Osobystist. Kyiv: Inform.-Analit. Ahenstvo.

Cherkunova, Marina. 2011. Pragmalinguisticheskije Kharakteristiki Annotatsij Uchebnoj i Nauchnoj Literatury: na Materiale Angloyazychnych Izdanij. Samara.

Shulinova, Larysa. 2010. “Anotatsia v Systemi Zhanriv Naukovoho Stylui Ukraiinskoii Literaturnoii Movy.” In: Movni i Kontseptualni Kartyny Svitu 29: 15-27. Kyiv: VD Dmytra Buraho.

Terekhova, Svitlana. 2017. "Referenstia v Angliiskij, Rosijskij ta Akrainskij Movakh: Prostir. Paradyhmalnist. Kontrast.” In: Die Welt der Slaven: Sammelbände 62 (20): $177-$ 187.

Armer, Tamzen. 2011. Cambridge English for Scientists. Cambridge: Cambridge University Press.

Fairclough, Norman. 2004. Analyzing Discourse. Textual Analysis for Social Research. London and New York: Routledge: Taylor \& Francis e-Library.

Katz, Jerrold. J., and Fodor, Jerry. A. 1963. The Structure of a Semantic Theory. In: Language, $39 \quad$ (2): 170-210. Accessed April 20, 2018: http://www.jstor.org/stable/411200?origin=JSTOR-pdf

Leong, Alvin P., Toh, Audrey L.L. 2018. "Examining the Structure in the Scientific Research Articles: A Study of Thematic Progression”. Written Communication, April 19. doi : $10.1177 / 0741088318767378$

Nelson, August. 2016. "Staatsolie's VISION 2030: the Contributions of Petroleum Geology to Surinamese Society". Netherland Journal of Geosciences 95 (4): 375-392.

Parafragou, Anna. 2006. "Epistemic Modality and Truth Conditions". Lingua 116, 1688-1702. Accessed April 15, 2018. http://papafragou.psych.udel.edu/papers/Linguaepmodality.pdf

Pryhodko, A. 2015. "Evaluative Modality in Language". Science and Education a New Dimension. Philology III (12), Issue 60: 78-80.

Powel, Mark. 2013. Presenting in English: how to Give Successful Presentaations. Thomson: Heinle.

Sperber Dan, Wilson, Deirdre. 1996. Relevance: Communication and Cognition. Oxford, Cambridge.

Schmidt, David. A. 2009. "Abstract Interpretation from a Denotational Semantics Perspective". In: Electronic Notes in Theoretical Computer Science.

Accessed May 3, 2018. http://santos.cs.ksu.edu/schmidt/MFPS09/paper.pdf 
Shannon Claude, Weawer Warren. 1986. "The Mathematical Theory of Communication". The Bell System Technical Journal 27: 379-423.

http://math.harvard.edu/ ctm/home/text/others/shannon/entropy/entropy.pdf

Zelinsky-Wibbelt, Cornelia. 2000. Discourse and the Continuity of Reference: Representing Mental Categorization. Berlin, N.Y.

Alsop, G.I., Marco, S., Levi, T., Weinberger, R. 2017. "Fold and Thrust Systems in Mass Transport Deposits". Journal of Structural Geology 94: 98-115.

Earney, Tait E., Baran Zeyner O. 2016. "A Case Study of Medical Geology: Investigation of the Occurrence of Erionite and Potential Enrichment Zones at Reva Gap in Harding County". The Geological Society of America. Paper presented at GSA Annual Meeting in Denver, Colorado, USA.

Rogers, David J., Ahmed, Farooq M., Ismail, Elamin. 2016. "Landslide Susceptibility Screening Using Wind-Driven Rainfall”. Environmental \& Engineering Geoscience 22 (4).

Riddhi, Dave, Aibing, Li. 2016. "Destruction of the Wyoming Craton: Seismic Evidence and Geodynamic Processes". Geology 44 (11).

Cambridge English Dictionary. Cambridge University Press. https://dictionary.cambridge.org

Modality. In Encyclopaedia Britannica. https://www.britannica.com/topic/modality

Varieties of Modality. In Stanford Encyclopaedia of Philosophy. First published Tue Nov 27, 2012. Stanford Encyclopaedia of Philosophy. https://plato.stanford.edu/entries/modality-varieties/ 